\title{
Activation in the family of Candida rugosa isolipases by polyethylene glycol
}

\author{
Cristina Otero ${ }^{\mathrm{a}, *}$, Mónica Fernández-Pérez ${ }^{\mathrm{a}}$, Juan A. Hermoso ${ }^{\mathrm{b}}$, \\ Martín Martínez Ripoll ${ }^{\mathrm{b}}$ \\ a Departamento de Biocatálisis, Instituto de Catálisis, CSIC, Campus Universitario, Cantoblanco, 28049 Madrid, Spain \\ b Grupo de Cristalografía Macromolecular y Biología Estructural, Instituto "Rocasolano" CSIC, Serrano 119, 28006 Madrid, Spain \\ Received 3 September 2004; accepted 2 December 2004 \\ Available online 15 January 2005
}

\begin{abstract}
We have investigated activation of two isoenzymes (lip1 and lip3) from Candida rugosa in polyethylene glycol (PEG) media. Aqueous solutions of PEG 8000 and 20,000 activate lip3 but not lip1 from C. rugosa. Maximum activation (260\%) of lip3 requires $6 \mathrm{~h}$ of pre-incubation with PEG $8000(4 \%$, w/v). PEG seems to shift the equilibrium between the open and the closed forms of lip 3 towards the active conformation. Inhibition experiments demonstrate that ligands have easier access to the lip3 active site than to the lip 1 active site, both in the presence and the absence of PEG.

The presence of PEG in the crystallization medium is responsible for reported differences in the crystal structures of lip1 and lip3. A comparative analysis of crystallographic models of lip1 and lip3 suggests a role for PEG in activation of lip3 and further stabilization of the activated/open form via dimerization in aqueous media.
\end{abstract}

(C) 2004 Elsevier B.V. All rights reserved.

Keywords: Lipase; Candida rugosa; Cholesterol esterase; Activation; Polyethylene glycol

\section{Introduction}

Lipases (triacylglycerol acylhydrolase, EC 3.1.1.3) are enzymes that "in vivo" hydrolyze the long chain aliphatic esters of triglycerides to produce fatty acids and glycerol. These enzymes have received extensive attention for their potential use in biotechnology [1].

One can distinguish different modes for activation of lipases at lipid-water interfaces [2]. The simplest case corresponds to displacement of a hydrophobic lid rendering a pre-formed active site accessible to the substrate [3]. In other cases, the oxyanion hole is formed only after the activation process. In the most complex case, a lipase may require the

Abbreviations: E600, Diethyl p-nitrophenyl phosphate; PEG, Polyethylene glycol; PNPB, $p$-Nitrophenyl butyrate; INH, Inhibitor

* Corresponding author. Tel.: +34 91 5854805; fax: +34 915854760.

E-mail address: Cotero@icp.csic.es (C. Otero). simultaneous presence of a colipase [4]. However, enzymes with lipolytic activity have been identified that do not exhibit the interfacial activation phenomenon. Consequently, the lack of interfacial activation is not a sufficient criterion for distinguishing lipases from esterases. A contemporary definition of lipases - carboxylesterases that are able to catalyze the hydrolysis of long-chain triacylglycerols [2,5] - includes (i) lipases with a lid covering the active site, for which the corresponding oxyanion is formed only after activation [4]; (ii) lipases containing a preformed oxyanion but which do not contain lid, and which do not exhibit activation, for example, Candida antarctica B [6] and cutinase [7]; and (iii) lipases having a lid and which exhibit interfacial activation, for example, lipases from Candida rugosa.

Interfacial activation of lipolytic enzymes is associated not only with the presence of one or more full-length loops covering the active site, but also the presence of other structural elements that might stabilize closed or open conformations 
of the lid [8]. In the case of pancreatic lipase, stabilization and adsorption to emulsified oil droplets are mediated by a preformed lipase-colipase-micelle complex $[9,10]$. Lipase activation involves different regions of the protein and is thus a complex phenomenon that must be further investigated.

Because isolipases from $C$. rugosa are characterized by lids covering the active site but differ in terms of their interactions with lipidic substrates [11,12], they constitute an appropiate system for further investigation of activation of lipases. A family of at least seven lipase genes has been described for C. rugosa, namely lip1-lip 7. lip1 and lip 3 can be isolated using a simple chromatographic purification process [13]. These isolipases are characterized by a high degree of homology in their sequences, the same molecular mass, and similar amino acid contents (ca. 79\%) [13]. They differ with respect to hydrophobicity, specificity and $\mathrm{p} I$ [12]. lipl and lip 3 also differ in their interactions with substrates at fluid interfaces [14].

lip1 has been crystallyzed in both open [15] and closed conformations [3]. Crystals of an uncomplexed and linoleatebound cholesterol esterase that is $100 \%$ identical in sequence to lip 3 have also been reported [16,17].

In the absence of any ligand, substrate or product, crystallization media containing polyethylene glycol (PEG) produces the open conformation of lip3 [18] and the closed conformation of lipl [3]. Consequently, we investigated the effects of PEG on the hydrolytic activity of these two different isoenzymes from $C$. rugosa in both the presence and absence of the inhibitor diethyl $p$-nitrophenyl phosphate (E600).

\section{Experimental}

\subsection{Materials}

Lipase type VII from C. rugosa, glycerol, diethyl pnitrophenyl phosphate and $p$-nitrophenyl butyrate (PNPB) were obtained from Sigma; 1-pyrenecarboxaldehyde (99\%) from Aldrich; and polyethylene glycol 8000 and 20,000 were obtained from Merck.

\subsection{Methods}

\subsubsection{Purification of lipases}

Purification of two extracellular lipases from C. rugosa was carried out according to the method reported previously [12]. Under the experimental conditions, none of the pure lipase solutions eluted from the chromatographic columns contained significant amounts of dimers. Only monomeric solutions of purified lipl and lip3 were employed in this study.

\subsubsection{Enzyme assays}

The activities of lipl and lip3 $\left(4.3 \times 10^{-8} \mathrm{M}, 0.77 \times\right.$ $\left.10^{-4} \mathrm{mg} / \mathrm{ml}\right)$ for the hydrolysis of PNPB $\left(1.7 \times 10^{-3} \mathrm{M}\right)$ were measured in sodium phosphate buffer $(0.1 \mathrm{M}, \mathrm{pH} 7)$ by following the accumulation at $30^{\circ} \mathrm{C}$ of PNPB at the isosbestic point of the nitrophenol/nitrophenolate couple ( $346 \mathrm{~nm}, \varepsilon=4800 \mathrm{M}^{-1} \mathrm{~cm}^{-1}$ ).

\subsubsection{Activation of enzymes with $P E G$}

lip1 and lip3 $\left(1.3 \times 10^{-5} \mathrm{M}\right)$ were incubated with $4 \%$ (w/v) PEG at $25^{\circ} \mathrm{C}$. Two types of PEG $(8000$ and 20,000$)$ were used in $0.1 \mathrm{M}$ sodium phosphate buffer $(\mathrm{pH}=7)$. The hydrolytic activities of both isoenzymes were measured at different incubation times over an $8 \mathrm{~h}$ period. For reference, the activity of the enzyme in the PEG-free medium was taken as $100 \%$.

\subsubsection{Enzymatic inhibition}

Isoenzymes lip1 and lip3 $\left(1.3 \times 10^{-5} \mathrm{M}\right)$ were first incubated for $6 \mathrm{~h}$ in phosphate buffer $\left(0.1 \mathrm{M}, \mathrm{pH} 7,25^{\circ} \mathrm{C}\right)$ in both the presence and absence of $0-5 \%$ (w/v) PEG 8000. Subsequently, sufficient E600 was added to the enzyme solution to produce a $0.26 \mathrm{mM}$ solution. The activities of these two enzyme solutions were measured at different times after addition of inhibitor. The residual activities are referenced to the corresponding enzyme activity before any treatment with activator/inhibitor.

\subsubsection{Fluorescence study}

Fluorescence of 1-pyrenecarboxaldehyde $\left(3.3 \times 10^{-4} \mathrm{M}\right)$ was used to detect changes in the dielectric constant of the medium. Fluorescence spectra of 1-pyrenecarboxaldehyde $\left(3.3 \times 10^{-4} \mathrm{M}\right)$ in the different incubation media used to treat the enzymes were recorded at $30^{\circ} \mathrm{C}$. A Perkin-Elmer fluorescence spectrometer (LS 50B) with excitation at $288 \mathrm{~nm}$ was used to obtain emission spectra at $250-600 \mathrm{~nm}$.

\section{Results}

\subsection{Effect of PEG on the activity of lip3}

Incubation of monomeric lip3 with 1-5\% (w/v) PEG 8000 for two hours increased the hydrolytic activity of this isolipase in aqueous solution (Table 1). The maximum increase in activity was observed following incubation with $4 \%(\mathrm{w} / \mathrm{v})$ PEG.

Table 1

Activity of Candida rugosa lip $3(0.06 \mathrm{mg} / \mathrm{ml})$ after incubation for two hours at $25^{\circ} \mathrm{C}$ with different percentages of PEG 8000 in $0.1 \mathrm{M}$ sodium phosphate buffer ( $\mathrm{pH} 7)$

\begin{tabular}{lll}
\hline PEG $8000(\%, w / v)$ & $\begin{array}{l}\text { Hydrolytic Activity } \\
\left(\mathrm{Umg}^{-1} \times 10^{-3}\right)\end{array}$ & Activity $(\%)$ \\
\hline 0 & 2.95 & 100 \\
1 & 3.95 & 134 \\
2 & 4.80 & 163 \\
3 & 5.15 & 174 \\
4 & 5.93 & 201 \\
5 & 5.0 & 169 \\
\hline
\end{tabular}



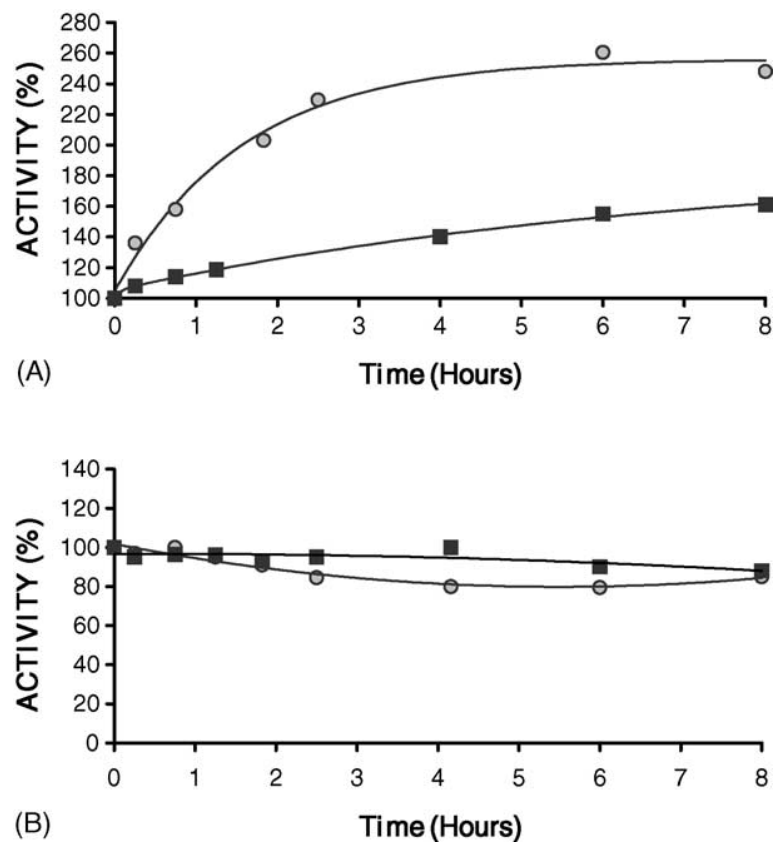

Fig. 1. Variation of the activity of C. rugosa isoenzymes $\left(1.3 \times 10^{-5} \mathrm{M}\right)$ in presence of PEG. Conditions: 4\% PEG (w/v) in sodium phosphate buffer (pH 7), $25^{\circ}$ C. (A): O, lip $3+$ PEG 8000;, lip 3 + PEG 20,000 and (B): O , lip 1+PEG 8000; $\mathbf{\square}$, lip 1+PEG 20,000.

\subsection{Effect of the molecular weight of PEG on the activities of $C$. rugosa isolipases}

Incubation in solutions containing 4\% (w/v) PEG 8000 and PEG 20,000 increased the hydrolytic activity of lip3 (Fig. 1A). The increase in activity was larger for PEG 8000 than for PEG 20,000. The extent of activation of the lipase following incubation with PEG also depends on the incubation time. The optimum incubation time was $6 \mathrm{~h}$ for lip3 $(260 \%$ activation). Maximum activation of lip3 (161\%) with PEG 20,000 requires $8 \mathrm{~h}$ of preincubation.

Unlike lip3, lip1 was not activated by incubation in solutions containing PEG (Fig. 1B).

\subsection{Inhibition of pretreated lipases}

Inhibition of both isoenzymes by $0.26 \mathrm{mM} \mathrm{E600} \mathrm{was} \mathrm{stud-}$ ied in the presence and the absence of 4\% (w/v) PEG 8000 (Fig. 2).

In the absence of PEG, incubation of lip 3 with the inhibitor for 5 min decreased the activity of lip 3 to $81 \%$ of the original value. By contrast, no change in activity was observed for lipl. These results indicate that in aqueous solution access of either substrates or inhibitors to the active site is easier for lip 3 than for lipl. The presence of PEG in the incubation medium increases inhibition of lip3 by E600 and leads to a residual activity of $37 \%$ after 5 min (Fig. 2). This effect was not observed for lipl.
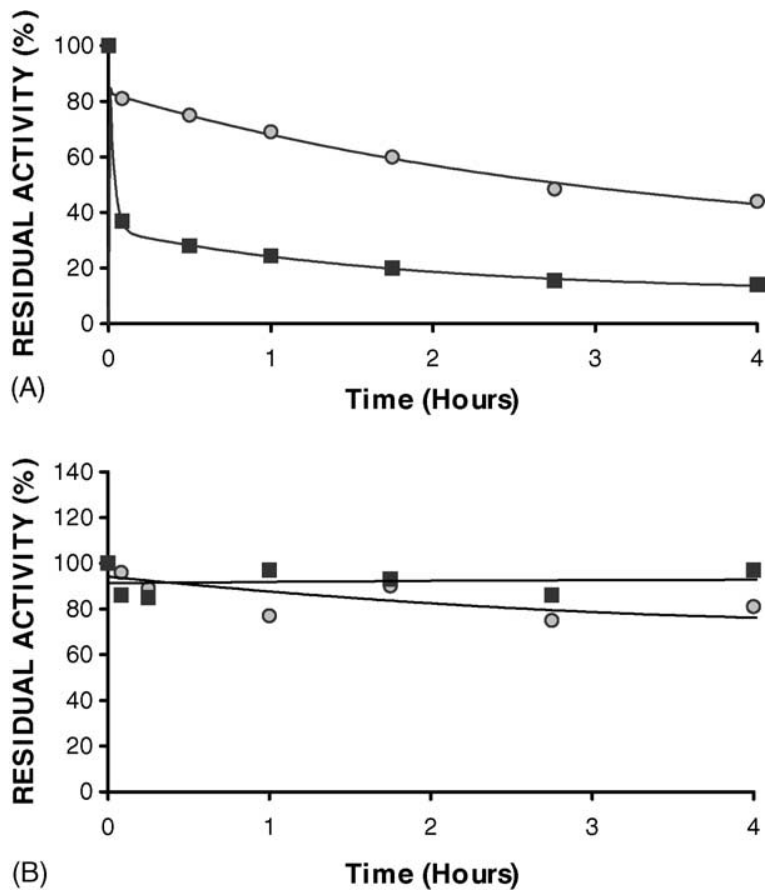

Fig. 2. Enzymatic activity after incubation of the isolipase with an inhibitor in the presence and absence of PEG. Conditions: $25^{\circ} \mathrm{C}, 1.3 \times 10^{-5} \mathrm{M}$ lipases in $0.1 \mathrm{M}$ sodium phosphate buffer ( $\mathrm{pH} 7), 0.26 \mathrm{mM} \mathrm{E600;} \mathrm{(A):} \mathrm{O,} \mathrm{lip} 3+\mathrm{INH}$; 口, lip $3+\mathrm{INH}+\mathrm{PEG} 8000$ and (B): O , lip $1+\mathrm{INH} ; \mathbf{\square}, l i p 1+\mathrm{INH}+\mathrm{PEG}$ 8000 .

\subsection{Study of the dielectric constants of different media}

Several authors [19-21] have indicated that the dielectric constant of the medium is responsible for conformational changes accompanying interfacial activation of lipolytic enzymes. Changes in the dielectric constant of the enzymatic solutions arising from the presence of PEG 8000 and 20,000 have been investigated by fluorescence (Table 2). Addition of glycerol $(50 \%, \mathrm{v} / \mathrm{v})$ produced shifts in the emission wavelength of 1-pyrenecarboxaldehyde similar to those observed for PEG 8000 . However, the activity of lip 3 is not affected by addition of glycerol to the buffer. Neither activation nor

Table 2

Fluorescence of 1-pyrenecarboxaldehyde $\left(3.3 \times 10^{-4} \mathrm{M}\right)$ at $30^{\circ} \mathrm{C}$ in different media (excitation at $288 \mathrm{~nm}$ )

\begin{tabular}{lll}
\hline Medium & $\begin{array}{l}\text { Dielectric } \\
\text { constant }(\varepsilon)\end{array}$ & $\begin{array}{l}\text { Emission peak } \\
(\mathrm{nm})\end{array}$ \\
\hline Methanol & 32.7 & 455.5 \\
PEG 6000 4\% $(\mathrm{w} / \mathrm{v})^{\mathrm{a}}$ & - & 465 \\
PEG 8000 4\% $(\mathrm{w} / \mathrm{v})^{\mathrm{a}}$ & - & 468 \\
Glycerol 50\% $(\mathrm{v} / \mathrm{v})^{\mathrm{a}}$ & $60.25^{\mathrm{b}}$ & 470 \\
PEG 20,000 4\% $(\mathrm{w} / \mathrm{v})^{\mathrm{a}}$ & - & 473 \\
Sodium phosphate buffer 0.1 M & - & 575 \\
Twice distilled water & 78.5 & 579
\end{tabular}

a $0.1 \mathrm{M}$ sodium phosphate buffer containing the indicated amount of PEG or glycerol.

${ }^{\mathrm{b}} \varepsilon_{\text {water }}=78.5 ; \varepsilon_{\text {Glycerol }}=42 ; \varepsilon_{\text {mixture }}=(50 \times 78.5)+(50 \times 42) / 100=60.25$ (if $\varepsilon$ of the $0.1 \mathrm{M}$ sodium phosphate buffer is equal to the value of $\varepsilon$ for the twice distilled water). 
deactivation of this isoenzyme was observed in this system when lip3 $\left(1.3 \times 10^{-5} \mathrm{M}\right)$ was incubated for $27 \mathrm{~h}$ at $25^{\circ} \mathrm{C}$ in $0.1 \mathrm{M}$ sodium phosphate buffer ( $\mathrm{pH} 7$ ) containing $50 \%(\mathrm{v} / \mathrm{v})$ glycerol.

\subsection{Structural analyses of C. rugosa lipases}

Analysis of the structures of these two isoenzymes reveals a large number of intramolecular interactions in lipl that favor stabilization of either the open or the closed forms of these isoenzymes (the Lys 85 -Glu 88 salt bridge in the open form and the Ser 450-Ser 84 hydrogen bond and two aromatic interactions of Phe 344 in the closed form of lipl are not present in lip3). Consequently, transitions between open and closed forms occur more readily in lip3 than in lip1. In aqueous solutions, the open form of lip3 is stabilized via dimerization of two protein molecules (primarily via hydrophobic interactions of a region involving the internal face of the lid) [18].

Protein-PEG complexes have been observed in the case of the FixJ receiver domain [22] and in a peptide deformylase [23] by using X-ray crystallography. In both proteins, non-specific hydrophobic and hydrogen bond interactions are established between the protein and the PEG.

\section{Discussion}

Comparison of the crystallization conditions and the conformations observed for a variety of lipases suggests that the conformation of the protein is determined by the dissolution medium [19-21]. However, closed structures of some lipases have been obtained in media that stabilize open forms of other lipolytic enzymes. C. rugosa lip1 requires the presence of an organic co-solvent (e.g., 2-methyl-2,4-pentanediol) to crystallize in open form [15]. By contrast, lip 3 crystallizes in its open conformation in aqueous media without the need for an organic co-solvent [18]. It seems that in C. rugosa isoenzymes the protein structure plays an important role in the activation process in media of relatively high dielectric constant.

PEG is a common component of solutions employed for crystallization of proteins. Crystals of $C$. rugosa lipases have been grown in PEG media $[3,16,18]$. The present study demonstrates the role of PEG 8000 and 20,000 in inducing conformational changes involving displacement of the lid covering the active site of lip3. The activation effect of displacement of the lid in lip 3 has been quantified. Displacement increases the hydrolytic activity of lip 3 by a factor of 2.6. The effects of inhibition of lip3 by E600 in the presence and absence of PEG have also been compared. The results suggest that PEG increases the displacement of the lid and facilitates inhibition of lip 3 by E600. This effect of PEG was observed only for lip3. By contrast, the closed conformation of lipl is not activated by PEG, nor is this enzyme significantly inhibited by E600 in media containing PEG.
Lip3 and lipl from C. rugosa have homologous structures as a consequence of their very high degree of sequence homology. However, for lip 3 the open form seems to be more favored than is the case for lip1. In the absence of PEG, lip3 is significantly inhibited by E600, while the activity of lipl is not affected by this solute (Fig. 2). The dimers of lip 3 are very stable in aqueous solutions relative to the corresponding situation for lipl. This fact agrees with reported observations that in both hydrophobic chromatography and reverse micelles, lip3 from C. rugosa establishes stronger interactions than lipl with the matrix and the micellar interface, respectively $[11,12]$. This aspect of the behavior of lip3 is also responsible for inhibition of this isoenzyme by E600 in the absence of PEG (Fig. 2). In addition, the experimental results can be explained in terms of the net effect of PEG molecules, which shifts the equilibrium between the closed and the open forms of lip3 towards to the open form. Hence, access of the inhibitor to the active site in lip3 is easier in the presence of PEG than in its absence. For lipl, where activation was not observed, the lid remains closed and the inhibitor does not enter the active site.

Failure to observe activation of lip 3 in a glycerol-water medium with a dielectric constant similar to that of the PEG solution (Table 2) suggests a direct role for PEG in the activation process, rather than an effect of the polarity of the medium. Computational studies of the conformations of three different lipases (H. lanuginosa, Rhizomucor miehei and $R$. delemar) suggest that the electrostatic interactions between residues located in the vicinity of the loop (the substrate contact zone) are relevant for lipase activation in hydrophobic environments [24]. In these three lipases, significant shifts in $\mathrm{p} K$ values for some residues in the loop have been observed when the lipases are activated in media of different dielectric constants [24]. Unlike the corresponding results obtained in non-polar media, our studies in aqueous media containing PEG demonstrate that the dielectric constant is not the factor responsible for activation of lip3.

Just as is the case for the FixJ receiver domain and the aforementioned peptide deformylase (see Section 3), a non specific interaction of PEG with lip3 from C. rugosa facilitates displacement of the lid, and the resulting open form of lip3 is subsequently stabilized via formation of relatively strong hydrophobic interactions with the partner molecule of the dimer. Solvation studies of $R$. miehei lipase have suggested an important role of the desolvation of Arg 86 in activation phenomena [25]. In C. rugosa lipases, the presence of PEG could be responsible for drastic changes in the solvation of one or more of the protein residues directly involved in activation of the lipase.

In lipl, a stabilization effect of the open form has been attributed to the carbohydrate attached at Asn 351 [26]. lipl and lip3 do not differ with respect to the indicated glycosylation site $[3,18]$.

The cholesterol esterase activated with bovine bile salt formed dimers with the active sites facing one another [27]. Similarly, crystallization of dimers of both lip1 and lip 3 from 
C. rugosa have been reported [17]. However, only in the case of lip3, has dimerization of the protein in aqueous solution been described [18]. As is the case for lip3, the hydrophobic side of the lid of lipl interacts with the symmetry related molecule in the dimer crystal. However, in lip1, the corresponding intermolecular forces do not determine the stability of the open conformation, since the intramolecular interactions between residues on the hydrophilic face of the lid and the adjacent protein surface are more extensive [15].

In summary, we have demonstrated that in aqueous solution, PEG activates lip3 but not lipl. The net effect of the PEG in solution is a shift of the equilibrium between the open and the closed forms of lip3. The presence of PEG in the crystallization medium could have determined the previously reported closed [3] and open [18] conformations of lip1 and lip3 from C. rugosa, respectively.

\section{Acknowledgements}

This work has been financed by the Spanish CICYT (PB92/0495 and BIO 96/0837). A predoctoral fellowship for M.F.P. was provided by the Autonomous Community of Madrid (Spain).

\section{References}

[1] T. Godfrey, S.I. West, Enzyme types and sources, in: T. Godfrey, S.I. West (Eds.), Industrial Enzymology, Macmillon Press Ltd., London, UK, 1996, pp. 3-6.

[2] R. Verger, Trends Biotechnol. 15 (1997) 32-38.

[3] P. Grochulski, Y. Li, J. Schrag, M. Cygler, Protein Sci. 3 (1994) 82-91.

[4] H. Van Tilbeurgh, M.P. Egloff, C. Martínez, N. Rugni, R. Verger, C. Cambillau, Nature 362 (1993) 814-820.

[5] P. Villeneuve, T.A. Foglia, INFORM 8 (1997) 640-648.

[6] M. Martinelle, M. Holmquist, K. Hult, Biochim. Biophys. Acta 1258 (1995) 272-276.
[7] C. Martínez, A. Nicolas, H. Van Tilbeurgh, M.P. Egloff, C. Cudrey, R. Verger, C. Cambillau, Biochemistry 33 (1994) 83-89.

[8] F. Carriere, K. Thirstrup, S. Hjorth, F. Ferrato, C. Withers-Martinez, C. Cambillau, E. Boel, L. Thim, R. Verger, Biochemistry 36 (1997) 239-248.

[9] J. Hermoso, D. Pignol, S. Penel, M. Roth, C. Chapus, J.C. FontecillaCamps, EMBO J. 18 (1997) 5531-5536.

[10] D. Pignol, L. Ayvazian, B. Kerfelec, P. Timmins, I. Crenon, J.A. Hermoso, J.C. Fontecilla-Camps, C. Chapus, J. Biol. Chem. 6 (2000) $4220-4224$

[11] C. Otero, M.L. Rúa, L. Robledo, FEBS Lett. 360 (1995) 202-206.

[12] M.L. Rúa, T. Díaz-Mauriño, V.M. Fernández, C. Otero, A. Ballesteros, Biochim. Biophys. Acta 1156 (1993) 181-189.

[13] M. Lotti, R. Grandori, F. Fusetti, S. Longhi, T. Brocca, L. Alberghina, Gene 124 (1993) 45-55.

[14] C. Otero, R. Castro, J. Soria, J. Phys. Chem. B 102 (1998) $8611-8618$

[15] P. Grochulski, Y. Li, J. Schrag, F. Bouthillier, P. Smith, D. Harrison, B. Rubin, M. Cygler, J. Biol. Chem. 268 (1993) 12843-12847.

[16] D. Ghosh, M. Erman, W.L. Duax, J. Steroid Biochem. Mol. Biol. 38 (1991) 663-665.

[17] D. Ghosh, Z. Wawrzak, V. Pletnev, N. Li, R. Kaiser, W. Pangborn, H. Jornvall, M. Erman, W. Duax, Structure 3 (1995) 279-288.

[18] R. Kaiser, M. Erman, W. Duax, W. Ghosh, H. Jörnvall, FEBS Lett. 337 (1994) 123-127.

[19] J. Schrag, Y. Li, M. Cygler, D. Lang, T. Burgdorf, H.J. Hecht, R. Schmid, D. Schomburg, T. Rydel, J. Oliver, L. Strickland, M. Dunaway, S. Larson, J. Day, A. McPherson, Structure 5 (1997) 187-202.

[20] S. Jääskeläinen, C. Verma, R. Hubbard, P. Linko, L. Caves, Protein Sci. 7 (1998) 1359-1367.

[21] S. Jääskeläinen, C. Verma, R. Hubbard, P. Linko, L. Caves, Theor. Chem. Acc. 101 (1999) 175-179.

[22] A. Becker, I. Schlichting, W. Kabsch, S. Schultz, F. Wagner, J. Biol. Chem. 273 (1998) 11413.

[23] G.H. Peters, S. Toxvaerd, O. Olsen, A. Svendsen, Protein Eng. 10 (1997) 137-147.

[24] P. Gouet, B. Fabry, V. Guillet, C. Birck, L. Mourey, D. Kahn, J.P. Samama, Structure (London) 7 (1999) 1517.

[25] F. Benedetti, F. Berti, L. Paolo, M. Stanislav, A. Sabot, Bioorg. Med. Chem. Lett. 6 (1996) 839-844.

[26] S. Brocca, M. Persson, E. Wehtje, P. Adlercreutz, L. Alberghina, M. Lotti, Protein Sci. 9 (2000) 985-990.

[27] X. Wang, C. Wang, J. Tang, F. Dyda, X. Zhang, Structure 5 (1997) 1209-1218. 